\title{
DNA double-strand breaks in the Toxoplasma gondii-infected cells by the action of reactive oxygen species
}

Haohan Zhuang ${ }^{1 \dagger}$, Chaoqun Yao ${ }^{2 \dagger}$, Xianfeng Zhao ${ }^{3}$, Xueqiu Chen ${ }^{1}$, Yimin Yang ${ }^{1}$, Siyang Huang ${ }^{4}$, Lingtao Pan ${ }^{1}$, Aifang Du ${ }^{1 *}$ (D) and Yi Yang ${ }^{1 *}$ (D)

\begin{abstract}
Background: Toxoplasma gondii is an obligate parasite of all warm-blooded animals around the globe. Once infecting a cell, it manipulates the host's DNA damage response that is yet to be elucidated. The objectives of the present study were three-fold: (i) to assess DNA damages in T. gondii-infected cells in vitro; (ii) to ascertain causes of DNA damage in T. gondii-infected cells; and (iii) to investigate activation of DNA damage responses during T. gondii infection.

Methods: HeLa, Vero and HEK293 cells were infected with T. gondii at a multiplicity of infection (MOI) of 10:1. Infected cells were analyzed for a biomarker of DNA double-strand breaks (DSBs) $\mathrm{YH} 2 \mathrm{AX}$ at $10 \mathrm{~h}, 20 \mathrm{~h}$ or $30 \mathrm{~h}$ post-infection using both western blot and immunofluorescence assay. Reactive oxygen species (ROS) levels were measured using 2',7'-dichlorodihydrofluorescein diacetate (H2DCFDA), and ROS-induced DNA damage was inhibited by a ROS inhibitor $\mathrm{N}$-acetylcysteine (NAC). Lastly, DNA damage responses were evaluated by detecting the active form of ataxia telangiectasia mutated/checkpoint kinase 2 (ATM/CHK2) by western blot.
\end{abstract}

Results: $\gamma H 2 A X$ levels in the infected HeLa cells were significantly increased over time during T. gondii infection compared to uninfected cells. NAC treatment greatly reduced ROS and concomitantly diminished YH2AX in host cells. The phosphorylated ATM/CHK2 were elevated in T. gondii-infected cells.

Conclusions: Toxoplasma gondii infection triggered DNA DSBs with ROS as a major player in host cells in vitro. It also activated DNA damage response pathway ATM/CHK2. Toxoplasma gondii manages to keep a balance between survival and apoptosis of its host cells for the benefit of its own survival.

Keywords: Toxoplasma gondii, DNA damage, Reactive oxygen species, DNA damage response

\section{Background}

The protozoan parasite Toxoplasma gondii infects almost all warm-blooded animals including humans worldwide [1]. It modulates some biological processes of the infected cell, such as autophagy and apoptosis, to

\footnotetext{
*Correspondence: afdu@zju.edu.cn; yangyi0607@zju.edu.cn

${ }^{\dagger}$ Haohan Zhuang, Chaoqun Yao, equal contributors

1 Institute of Preventive Veterinary Medicine, Zhejiang Provincial Key

Laboratory of Preventive Veterinary Medicine, College of Animal Sciences,

Zhejiang University, Hangzhou 310058, PR China

Full list of author information is available at the end of the article
}

facilitate its survival and proliferation [2, 3]. DNA damage was also reported in the retina and the peripheral blood cells of T. gondii-infected mice $[4,5]$. However, it remains to be elucidated how T. gondii causes host DNA damage and what the DNA damage responses are. DNA damage appears in different forms such as singlestrand breaks (SSBs), double-strand breaks (DSBs), missing bases and chemical modification of bases, etc. [6]. DNA damage may be caused by various endogenous or exogenous factors. Examples are reactive

c) The Author(s) 2020. This article is licensed under a Creative Commons Attribution 4.0 International License, which permits use, sharing, adaptation, distribution and reproduction in any medium or format, as long as you give appropriate credit to the original author(s) and the source, provide a link to the Creative Commons licence, and indicate if changes were made. The images or other third party material in this article are included in the article's Creative Commons licence, unless indicated otherwise in a credit line to the material. If material is not included in the article's Creative Commons licence and your intended use is not permitted by statutory regulation or exceeds the permitted use, you will need to obtain permission directly from the copyright holder. To view a copy of this licence, visit http://creativeco mmons.org/licenses/by/4.0/. The Creative Commons Public Domain Dedication waiver (http://creativecommons.org/publicdomain/ zero/1.0/) applies to the data made available in this article, unless otherwise stated in a credit line to the data. 
oxygen species (ROS) and ultraviolet light and chemical reagents, respectively [7].

ROS are naturally generated from metabolic and biochemical reactions and are a major source of the endogenous stress [8]. Superoxide, hydrogen peroxide, hydroxyl radicals and singlet oxygen are all ROS. High levels of ROS can oxidize DNA molecules leading to base oxidization, SSBs and DSBs [9]. Increasing lines of evidence clearly show that ROS are triggered by bacterial, viral and parasitic pathogens in host cells during infection [10]. Further, ROS affect DNA integrity of host cells although it is debatable whether ROS are always detrimental to infecting pathogens [11].

According to its virulence in the mouse model, the protozoan $T$. gondii is divided into three vastly different virulent groups, i.e. Type I, II and III. Interestingly, infections by both avirulent Type III (CTG strain) and virulent Type I (GT1 strain) trigger ROS production in the infected macrophages. CTG-strain parasites are mainly cleared by the naive macrophages in a manner depending on NADPH oxidase-generated ROS without activation of interferon gamma [12]. Due to ROS' potential detrimental impact on DNA, we explored the association between elevated ROS levels and host DNA damage during $T$. gondii infection. We used $\gamma \mathrm{H} 2 \mathrm{AX}$, a well-characterized marker for DNA DSBs, to demonstrate DNA damage in T. gondii-infected HeLa cells. $\gamma \mathrm{H} 2 \mathrm{AX}$ levels increased over time during T. gondii infection and ROS was the major player in the DNA DSBs. Furthermore, the DNA damage response pathway ataxia telangiectasia mutated/ checkpoint kinase 2 (ATM/CHK2) was activated, suggesting roles of DNA damage in regulation of other biological processes as well in these T. gondii-infected host cells. Together, our data reveal the major role of ROS in host DNA damage during T. gondii infection, and lay a foundation for better understanding how $T$. gondii interacts with its host from the view of DNA damage.

\section{Methods}

\section{Cells, parasites and mice}

Vero, HEK293T and HeLa cells were all obtained from the Cell Bank of the Chinese Academy of Sciences (Shanghai, China). The cells were cultured in DMEM (Biological Industries, Kibbutz, Israel) supplemented with a final concentration of $10 \%$ fetal bovine serum (FBS) (Biological Industries) and 1\% penicillin-streptomycin-glutamine (Gibco, Carlsbad, USA). All cells were treated with MycAway ${ }^{\mathrm{TM}}$ elimination reagent (Yeason, Shanghai, China), followed by testing using One-Step Mycoplasma Detection Kit (Yeason) to make sure they were Mycoplasma free. Both the T. gondii RH $\Delta k u 80$ strain and EGFP-RH $\Delta k u 80$ strain were serially passaged as tachyzoites in Vero cells in our own laboratory as previously described [13]. Briefly, tachyzoites were collected in the supernatant of centrifugation of spontaneously ruptured $T$. gondii-infected Vero cells at $300 \mathrm{~g}$ for $5 \mathrm{~min}$ at room temperature. They were further cleaned by passing through a syringe filter of $5-\mu \mathrm{m}$ pore size (Millipore, Darmstadt, Germany). Parasites were used to infect fresh Vero cells at a multiplicity of infection (MOI) of 10:1 after quantification using a hemocytometer. Six-week-old BALB/c mice were obtained from Shanghai SLAC Laboratory Animal Co., Ltd (Shanghai, China), and housed in a ventilated cage kept under a conditioned temperature of $25^{\circ} \mathrm{C}$ with a light/dark cycle of $14 \mathrm{~h} / 10 \mathrm{~h}$.

\section{Antibodies and mouse sera}

The antibodies to the following molecules were purchased from various sources as indicated. $\gamma \mathrm{H} 2 \mathrm{AX}$ (20E3, Cell Signaling Technology, Danvers, USA) was used to detect DNA DSBs. Actin and the cleaved caspase 3 (Abcam, Cambridge, UK) were used as a loading control and apoptotic marker, respectively. ATM, ATMS1981, CHK2 and CHK2-T68 (Cell Signaling) were used to document DNA damage responses. HRP-conjugated goat anti-mouse IgG and anti-rabbit IgG (Fude, Hangzhou, China) were used in the western blot. Donkey antimouse Alexa Fluor 488 and goat anti-rabbit Alexa Fluor 594 (Invitrogen, Carlsbad, USA) were used in the immunofluorescence assay (IFA). Anti-T. gondii inner membrane complex 1 (IMC1) and surface protein 1 (SAG1) mouse sera, kind gifts from colleagues Miss Mi Lin and Miss Mingxiu Zhao (College of Animal Sciences, Zhejiang University), were used to detect T. gondii in IFA and western blot, respectively. Toxoplasma gondii positive serum was harvested from BALB/c mice 6 days postinfection (pi) and used to block T. gondii invasion into HeLa cells. Negative serum was collected from the same mice prior to infection and used as controls.

\section{Western blot}

Western blot was carried out as previously described [13]. Briefly, cells were lysed by incubation for $30 \mathrm{~min}$ in ice-cold radioimmunoprecipitation assay lysis buffer supplemented with a protease inhibitor cocktail (Bimake, Shanghai, China). The soluble proteins derived from the supernatants of the centrifugation of the cellular lysates at $12,000 \mathrm{~g}, 4^{\circ} \mathrm{C}$ for $10 \mathrm{~min}$ were measured using a BCA assay kit (Fude, Hangzhou, China) and were then subjected to SDS-PAGE. The $0.22 \mu \mathrm{m}$ PVDF membrane (Millipore, Darmstadt, Germany) blotted with proteins was blocked with 5\% skimmed milk (Sangon, Shanghai, China) in Tris buffered saline containing 0.5\% Tween20 (TBST) followed by incubation in suitable primary 
antibodies. The membranes were then probed with appropriate HRP-conjugated secondary antibodies (Fude). Membranes were rinsed thrice in TBS (10 $\mathrm{min}$ each) at each interval. Signals were immediately documented using the ChemiDoc ${ }^{\mathrm{TM}}$ chemiluminescence system (Bio-Rad, Hercules, USA) after membranes were exposed to ECL substrates (Fude).

\section{IFA}

IFA was carried out as previously described [12]. Briefly, cells grown on coverslips in a 24-well plate were fixed with $4 \%$ paraformaldehyde in phosphate-buffered saline (PBS) for $10 \mathrm{~min}$ and permeabilized with $0.25 \%$ tritonPBS for $10 \mathrm{~min}$. They were incubated with the primary antibodies for $1 \mathrm{~h}$ after being blocked in $1 \%$ bovine serum albumin for $1 \mathrm{~h}$ followed by submerging in suitable Alexafluor-conjugated secondary antibodies for $1 \mathrm{~h}$ in the dark. Afterwards they were counterstained with DAPI (SigmaAldrich, Saint Louis, USA) for $1 \mathrm{~min}$. At each interval, the cells were rinsed thrice with PBS (10 min each). The coverslips were then mounted to a glass slide and cell images were obtained using an Olympus IX81 FV1000 confocal microscope (Olympus, Monolith, Japan).

\section{ROS measurement}

ROS measurement and inhibition was carried out as previously described $[14,15]$. Briefly, HeLa cells were seeded on 24-well plates and infected with $T$. gondii $\mathrm{RH} \Delta k u 80$ strain parasites at a multiplicity of infection (MOI) of 10:1. Twenty-four hours post-infection (hpi), infected cells were treated with the ROS inhibitor N-acetylcysteine (NAC) at $50 \mu \mathrm{m}$ for $1 \mathrm{~h}, 2 \mathrm{~h}$ or $4 \mathrm{~h}$. NAC, a precursor of cysteine and glutathione, cellularly functions as an antioxidant via the redox potential of thiols or via increasing glutathione levels [16]. Following NAC treatment and after being rinsed 3 times in PBS, infected cells were incubated in $10 \mu \mathrm{m} \mathrm{2} 2^{\prime}, 7^{\prime}$-dichlorodihydrofluorescein diacetate (H2DCFDA; MCE, Monmouth, USA) in the dark at $37^{\circ} \mathrm{C}$ and $5 \% \mathrm{CO}_{2}$ for $30 \mathrm{~min}$. H2DCFDA is a non-fluorescent precursor that is intracellularly oxidized by ROS to form a highly fluorescent product DCF. Finally, fluorescence signals of cells were measured using a Synergy 2 plate reader (Biotek, Winooski, USA) at $485 \mathrm{~nm}$ exiting wavelength.

\section{Quantification and statistical analysis}

Quantification of the western-blot protein bands was performed by Image J. Western blot data from Image J and fluorescence data from a plate reader representing triplicate samples were analyzed by GraphPad Prism 7.0 (GraphPad, La Jolla, USA). Statistical analysis was performed by one-way ANOVA and Student's t-test with $P \leq 0.05$ being considered significant.

\section{Results}

\section{Toxoplasma gondii infection triggered DNA DSBs in host} cells in vitro

DSBs are one of the most common forms of DNA damage [17]. Phosphorylation at the ser 139 position of H2AX named $\gamma \mathrm{H} 2 \mathrm{AX}$ is a well-characterized DSBs marker of the mammalian cells [18]. To study host cell DNA damage by $T$. gondii infection in vitro, we infected Vero, HEK293T or HeLa cells with T. gondii RH $\Delta k u 80$ strain parasites at a MOI of 10:1. A similar effect was observed among all the three types of cells upon T. gondii infections. Hela cells were used throughout the entire study description here unless another cell type was specifically identified. The cells were harvested at $0 \mathrm{~h}$ (uninfected control) 10,20 or $30 \mathrm{hpi}$ and analyzed by western blot to detect $\gamma \mathrm{H} 2 \mathrm{AX}$. Compared to $0 \mathrm{~h}, \gamma \mathrm{H} 2 \mathrm{AX}$ levels in the infected HeLa cells at $10 \mathrm{~h}, 20 \mathrm{~h}$, and $30 \mathrm{~h}$ had increased approximately 10-, 85- and 90-fold (10 h: ANOVA, $F_{(3,8)}=13.87, P=0.0323 ; 20$ h: ANOVA, $F_{(3,8)}=13.87$, $P=0.0002 ; 30 \mathrm{~h}$ : ANOVA, $\left.F_{(3,8)}=13.87, P=0.0005\right)$ (Fig. 1a, b), respectively. A similar trend was observed in the infected Vero and HEK293T cells as well (data not shown). We next determined the source of $\gamma \mathrm{H} 2 \mathrm{AX}$ since Fig. 1a, b did not show whether it originated from the infected host cells, parasites themselves or both. Tachyzoites were harvested by passing the infected Hela cells at $24 \mathrm{hpi}$ through a 27 -gauge syringe needle numerous times. They were then cleaned up with a $5-\mu \mathrm{m}$ filter followed by cellular lysis by sonication. Their $\gamma \mathrm{H} 2 \mathrm{AX}$ levels were contrasted to those of the infected cells by western blot. $\gamma \mathrm{H} 2 \mathrm{AX}$ was abundantly detected in the infected $\mathrm{HeLa}$ cells. In contrast, $\gamma \mathrm{H} 2 \mathrm{AX}$ levels in parasites themselves were below the detectable level (Fig. 1c). These data clearly show that $\gamma \mathrm{H} 2 \mathrm{AX}$ predominately originated from the host cells rather than the parasites. To confirm $\gamma \mathrm{H} 2 \mathrm{AX}$ location in $T$. gondii infected cells, we carried out IFA using anti-IMC1 mouse serum and antibody to $\gamma \mathrm{H} 2 \mathrm{AX}$ to pinpoint $T$. gondii and DNA damage, respectively. Relative to uninfected cells, highly elevated $\gamma \mathrm{H} 2 \mathrm{AX}$ signals were detected in the nuclei of $T$. gondii-infected HeLa cells 20 or 30 hpi (Fig. 1d). Taken together, our data unequivocally demonstrated that $T$. gondii infection induced DSBs in host cells in vitro.

\section{Toxoplasma gondii induced DSBs were irrelevant to apoptosis and depended on its invasion}

It has been reported that $\gamma \mathrm{H} 2 \mathrm{AX}$ occurs in early apoptosis when DNA fragmentation just starts [19]. Toxoplasma gondii initiates apoptosis in some type of cells whereas it inhibits the process in others [20]. Our next experiments tested whether apoptosis influenced $\gamma \mathrm{H} 2 \mathrm{AX}$ levels during T. gondii infection. To this end, HeLa cells were treated with staurosporine, an apoptosis inducer [21], at 


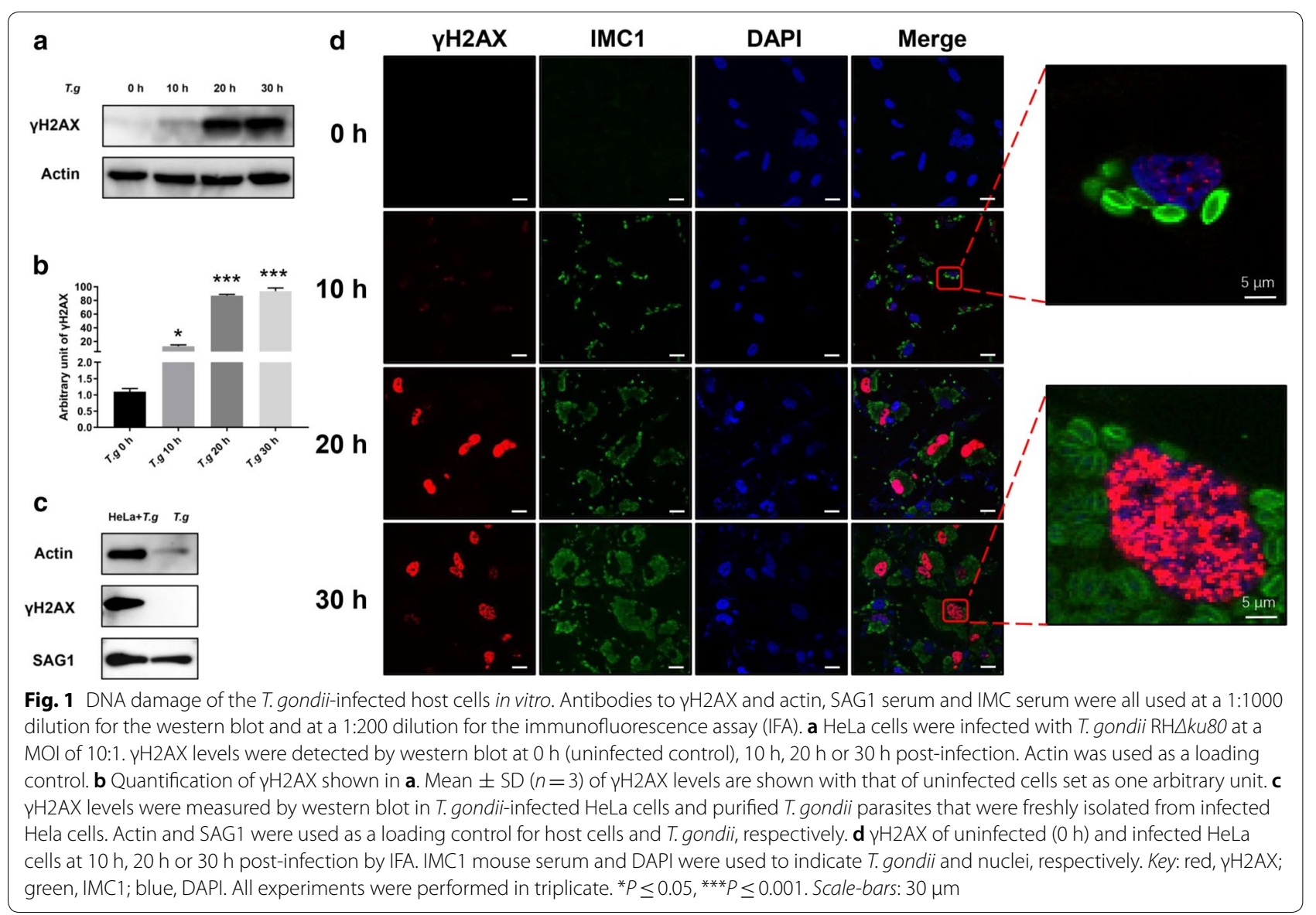

$1 \mu \mathrm{m}$ for $4 \mathrm{~h}$ and apoptosis was monitored by an early apoptotic signal, the cleaved caspase 3 in the western blot [22]. While $\gamma \mathrm{H} 2 \mathrm{AX}$ were detected in both staurosporinetreated HeLa cells and T. gondii-infected (12 $\mathrm{h}$ and $24 \mathrm{~h}$ ) HeLa cells, the cleaved caspase 3 was only detected in staurosporine-treated cells with no trace of it being detected in T. gondii-infected cells (treated: ANOVA: $F_{(3,8)}=80.51, P=0.0003 ; 12$ h: ANOVA: $F_{(3,8)}=80.51$, $P=0.0002 ; 24$ h: ANOVA: $\left.F_{(3,8)}=80.51, P=0.0003\right)$ (Fig. 2a, b). These data clearly showed that T. gondii infection did not trigger apoptosis in HeLa cells, which unequivocally ruled out that apoptosis was involved in their DNA damage.

During early infection, $T$. gondii invades host cells and leads to the formation of a parasitophorous vacuole to facilitate its proliferation [23]. We next examined whether $T$. gondii triggered host DNA damage before invasion. To this end, EGFP-RH $\Delta k u 80$ T. gondii tachyzoites were incubated with either positive serum from T. gondii-infected $\mathrm{BALB} / \mathrm{c}$ mice or negative control serum for $1 \mathrm{~h}$ at $37{ }^{\circ} \mathrm{C}$ prior to infection as previously reported [24]. The positive serum was used to block the invasion of T. gondii. HeLa cells were then infected with serum-treated T. gondii at a MOI of 10:1, infected cells were imaged by fluorescence microscopy to detect EGFP $24 \mathrm{hpi}$ or harvested for western blot analysis of $\gamma \mathrm{H} 2 \mathrm{AX}$ at 20 hpi. Compared with negative serum treatment, positive serum treatment dramatically blocked invasion of T. gondii, and decreased $\gamma \mathrm{H} 2 \mathrm{AX}$ levels by approximately 98\%. (Student's t-test: $t_{(2)}=17.91, P=0.0002$ ) (Fig. 2c, d). These results strongly indicate that induction of host DNA damage depends on the invasion of T. gondii.

\section{ROS contributed to host DNA damage}

ROS induce oxidative stress, which turns out to cause damages to macromolecules such as DNA, proteins and lipids [25]. Multiple studies have suggested pathogeninduced ROS role in host-cell DNA damage [26-30]. Elevated ROS levels have been reported in $T$. gondiiinfected host cells [12, 31]. We hypothesized that ROS cause host DNA damage during T. gondii infection. To test this hypothesis, we treated $T$. gondii infected HeLa cells with N-acetylcysteine (NAC), a ROS inhibitor. NAC was applied to the infected cells $24 \mathrm{hpi}$ for up to $4 \mathrm{~h}$. Two methods were used to gauge the impact of ROS on 


\section{a}

$1 \mu \mathrm{m}$ Staurosporine

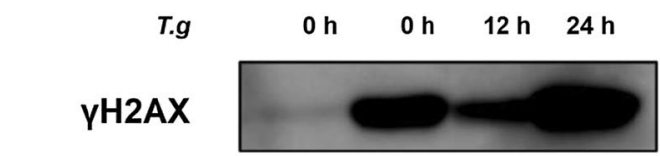

Cleaved
Caspase 3

Actin
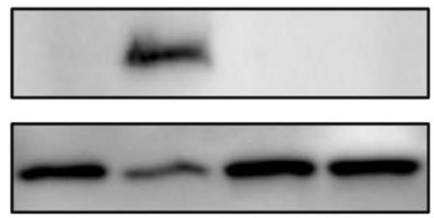

C

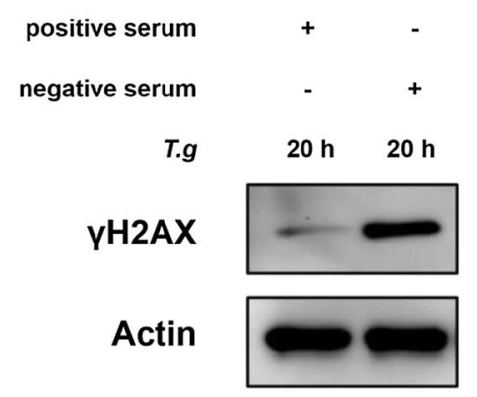

b

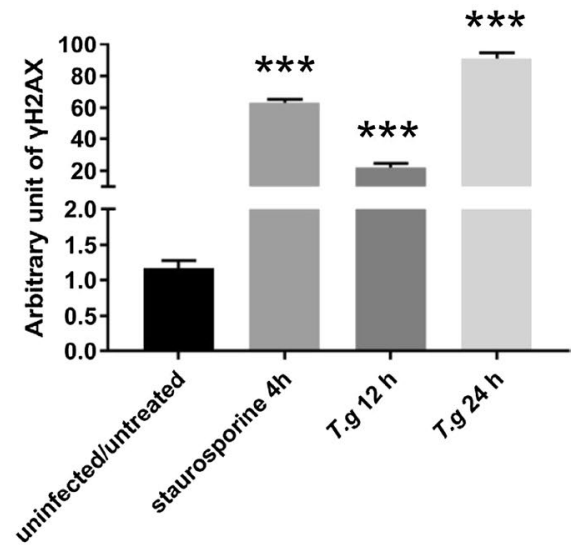

d

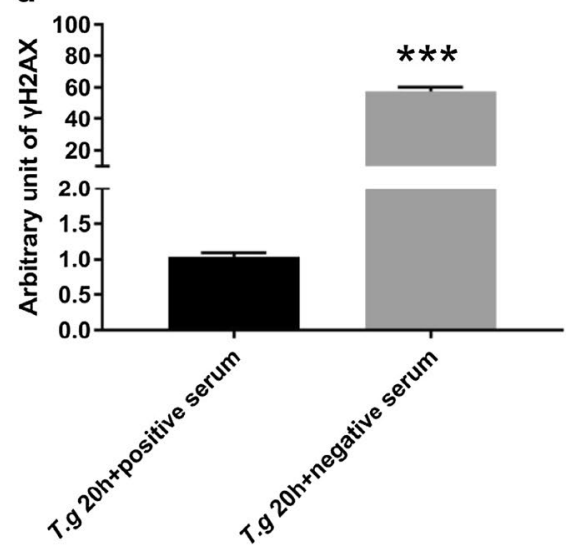

Fig. 2 DNA damage of T. gondii-host cells upon its invasion. Antibodies to $\mathrm{YH} 2 \mathrm{AX}$, actin, and the cleaved caspase 3 were all used at a 1:1000 dilution. a Uninfected HeLa cells were treated with $1 \mu \mathrm{m}$ staurosporine for $4 \mathrm{~h}$ to induce apoptosis. Treated, uninfected and infected HeLa cells were harvested $12 \mathrm{~h}$ or $24 \mathrm{~h}$ later, $\mathrm{YH} 2 \mathrm{AX}$ and the cleaved caspase 3 were detected by western blot. b Quantification of $\mathrm{\gamma H} 2 \mathrm{AX}$ shown in $\mathbf{a}$. Mean $\pm \mathrm{SD}$ $(n=3)$ of $\gamma \mathrm{H} 2 \mathrm{AX}$ levels are shown with that of uninfected cells set as one arbitrary unit. $\mathbf{c} \gamma \mathrm{H} 2 \mathrm{AX}$ was detected by western blot on HeLa cells $20 \mathrm{~h}$ post-infection with positive or negative serum-pretreated EGFP-RH $\triangle$ ku80. d Quantification of $\gamma H 2 A X$ shown in c. Mean $\pm S D(n=3)$ of $\gamma H 2 A X$ levels are shown with that of uninfected cells set as one arbitrary unit. All experiments were performed in triplicate. ${ }^{* * *} P \leq 0.001$

host DNA damage. First, ROS levels of uninfected cells, host cells and NAC-treated host cells were analyzed using H2DCHFA, a non-fluorescent precursor that is converted to fluorescent DCF by ROS. H2DCHFC has been widely used as a probe to detect ROS for 50 years. It detects hydrogen peroxide, hydroxyl radicals and singlet oxygen but not superoxide anion [32]. The higher the ROS level is, the stronger florescence signal it produces. The second method was to monitor generation of $\gamma \mathrm{H} 2 \mathrm{AX}$ by western blot and IFA. The results show that ROS levels in the infected Hela cells increased by approximately $70 \%$ compared to those of uninfected cells 24 hpi by fluorescence quantification. NAC treatment for as little as $1 \mathrm{~h}$ completely offset the influence of $T$. gondii infection by bringing the ROS levels down almost to the basic level of the uninfected cells (infected: ANOVA: $F_{4}$,
${ }_{10)}=38.85, P=0.0002$; NAC 4 h: ANOVA: $F_{(4,10)}=38.85$, $P=0.8755$; NAC 2 h: ANOVA: $F_{(4,10)}=38.85, P=0.9321$; NAC 1 h: ANOVA: $F_{(4,10)}=38.85, P=0.8652$ ) (Fig. 3a). Western blot showed that $\gamma \mathrm{H} 2 \mathrm{AX}$ levels in the NACtreated infected host cells reduced by approximately $85 \%, 85 \%$ and $70 \%$ at 1,2 and $4 \mathrm{~h}$ of NAC treatment, respectively, compared to those of the untreated infected host cells (infected: ANOVA: $F_{(4,10)}=47.55, P=0.0002$; NAC 4 h: ANOVA: $F_{(4,10)}=47.55, P=0.0005$; NAC 2 h: ANOVA: $F_{(4,10)}=47.55, P=0.0341$; NAC 1 h: ANOVA: $F_{(4,10)}=47.55, P=0.0325$ ) (Fig. 3b, c); quantification of protein bands were performed by Image J. IFA confirmed this dramatic reduction in $\gamma \mathrm{H} 2 \mathrm{AX}$ levels in NAC-treated host cells compared to untreated host cells. Further, $\gamma \mathrm{H} 2 \mathrm{AX}$, although weak, remained detectable in these NAC-treated cells (Fig. 3d). These two lines of evidence 


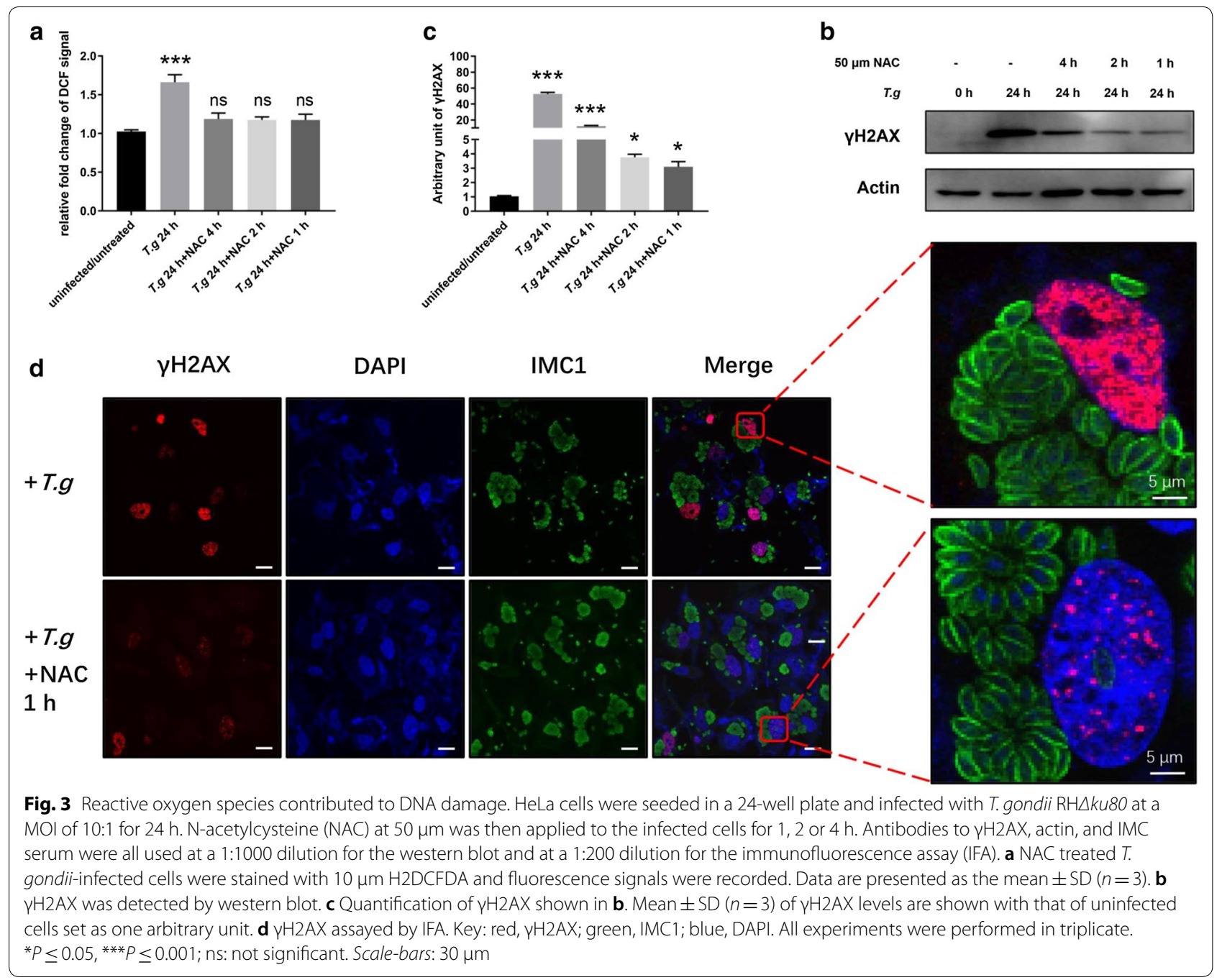

suggested that diminishing ROS by NAC greatly reduced $\gamma \mathrm{H} 2 \mathrm{AX}$ levels in infected cells, indicating that ROS leads to DNA damage during T. gondii infection.

\section{Host DNA damage response pathway ATM/CHK2 was activated by $T$. gondii infection}

DNA damage response is triggered upon DNA damage in the eukaryotic cells. A network of kinase pathways is involved in this biological process, among which ATM/ CHK2 and ATM RAD3-related/checkpoint kinase 1 (ATR/CHK1) are two main pathways responding to DSBs and SSBs, respectively [17]. Since we had already detected DSBs in host cells, we then examined whether ATM/CHK2 pathway was activated in the $T$. gondiiinfected cells. ATM-S1981 and CHK2-T68 are the functionally activated form of ATM and CHK2, respectively [17]. The levels of ATM-S1981 and CHK2-T68 quantified by western blot were approximately 10-, 65-, 70-fold and 1-, 15-, 25-fold, respectively at 10, 20 and $30 \mathrm{hpi}$ compared to the uninfected controls of $0 \mathrm{~h}$ (ATM-S1981 $10 \mathrm{~h}:$ ANOVA: $F_{(3,8)}=34.28, P=0.0002 ; 20 \mathrm{~h}$ : ANOVA: $F_{(3,8)}=34.28, P=0.0003$; 30 h: ANOVA: $F_{(3,8)}=34.28$, $P=0.0005$; CHK2-T68 10 h: ANOVA: $F_{(3,8)}=54.92$, $P=0.9981 ; 20$ h: ANOVA: $F_{(3,8)}=54.92, P=0.0003 ; 30 \mathrm{~h}:$ ANOVA: $\left.F_{(3,8)}=54.92, P=0.0006\right)$ (Fig. $4 \mathrm{a}-\mathrm{c}$ ). This result indicated that the ATM/CHK2 pathway was activated during T. gondii infection.

\section{Discussion}

DNA damage is classified as SSBs, DSBs, and chemical modification of bases. These different types of DNA damage can be detected by various markers. We used $\gamma \mathrm{H} 2 \mathrm{AX}$ to detect DNA DSBs in the T. gondii infected cells. Other types of DNA damage in the eukaryotic cells can be identified by corresponding suitable markers. For example, anti-8oxoG antibody can be used to detect chemical 

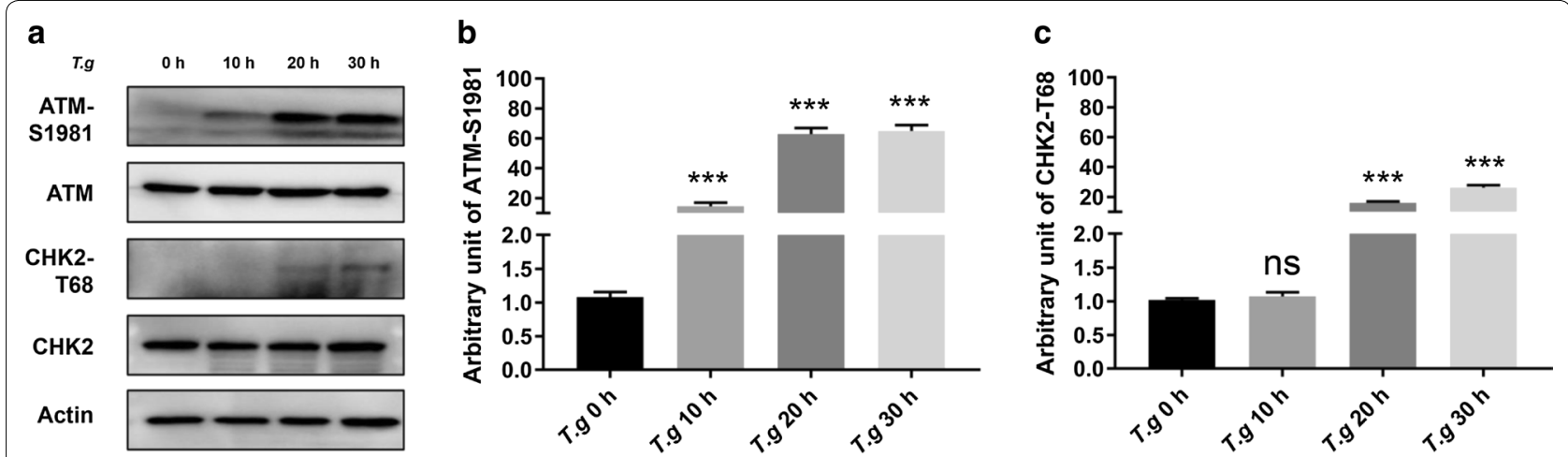

Fig. 4 ATM/CHK2 activation upon T. gondii infection. a HeLa cells were infected with T. gondii RH $\triangle k$ ku80 at a MOI of 10:1. Expression of ATM, ATM-S1981, CHK2 and CHK2-T68 were detected by western blot at $0 \mathrm{~h}$ (uninfected control), $10 \mathrm{~h}, 20 \mathrm{~h}$ or $30 \mathrm{~h}$ post-infection. All antibodies were used at a 1:1000 dilution. b Quantitation of ATM-S1981 shown in a with ATM-S1981 levels of uninfected cells set as one arbitrary unit. c Quantitative data of CHK2-T68 shown in a with CHK2-T68 levels of uninfected cells set as one arbitrary unit. Data are presented as the mean \pm SD $(n=3)$. All experiments were performed in triplicate. ${ }^{* *} P \leq 0.001$; ns: not significant

modification of DNA bases under oxidative stress [33, 34]. Here, DSBs were clearly demonstrated in the T. gondiiinfected host cells. Evaluation of other types of DNA damage in these cells is beyond the scope of the present paper and waits to be further performed. Whether T. gondii cells themselves show DSBs is worthy of a brief discussion. We did not detect them in both western blot and IFA using the antibody to $\gamma \mathrm{H} 2 \mathrm{AX}$. Nevertheless, a basal level of DSBs in proliferating $T$. gondii has been previously reported [35]. One plausible reason for this discrepancy is that the different monoclonal antibodies $(\mathrm{mAb})$ to $\gamma \mathrm{H} 2 \mathrm{AX}$ are used in the two studies. Our mAb (20E3), was purchased from Cell Signaling Technology, whereas the mAb (JBW301) in the previous study was purchased from Merck Argentina. mAbs to the same protein may recognize different epitopes. Alternatively, this discrepancy may be due to the different binding capacity of the two mAbs.

It has been reported that $T$. gondii infection inhibits apoptosis of host cells [36]. According to our data, $T$. gondii infections do not cause apoptosis in its host cells which aligns well with these earlier reports even though they do not exactly confirm inhibition of apoptosis in the infected cells. In our experiment of blocking invasion of T. gondii, one shortcoming of using mouse serum to inhibit the invasion of host cells by T. gondii is that there might exist antibodies to the molecules that play important roles other than its invasion. Reagents that have been proven to block this parasite invasion are alternatives. This can be achieved by the reagent's action on either the T. gondii tachyzoites or host cells. One example of the former is protease inhibitors such as BAY11-7082 [37]. The latter includes dynamin inhibitor such as dynasore, a small chemical compound that inhibits dynamin GTPase activity [38]. Due to the technical challenges these compounds were not used in the present study. Nevertheless, the mouse serum containing polyclonal antibodies used in the current study indeed block the parasites' invasion of HeLa cells (see Additional file 1: Figure S1).

ROS are inhibited by activating antioxidant enzymes, such as catalase, superoxide dismutase and glutathione peroxidase, or by non-enzymatic antioxidants, such as glutathione and thioredoxin. ROS inhibitor NAC reacts with hypochlorous acid, hydroxyl radical and hydrogen peroxide but not superoxide anion [39]. Our data clearly demonstrated that ROS inhibition by NAC decreased $\gamma \mathrm{H} 2 \mathrm{AX}$ levels by a minimum of $70 \%$, leaving a maximum of $30 \% \gamma \mathrm{H} 2 \mathrm{AX}$ intact. This may be due to the action of superoxide anion, which can be addressed later in a follow-up study by its specific inhibitors such as eugenol, chalcone and derivative, 3 '-isopropoxychalcone (H2O7D) $[40,41]$. Our result showed that T. gondii infection causes a significant increase in the level of ROS in HeLa cells. Although consistent with some earlier reports [12, 31], these are clearly contradicted to at least one other study. Decreased levels of ROS were observed in T. gondiiinfected ARPE-19 cells, a human RPE cell line, that had also been exposed to $\mathrm{H}_{2} \mathrm{O}_{2}$ treatment, and T. gondiiinfected ARPE-19 cells at a MOI of 5:1 without $\mathrm{H}_{2} \mathrm{O}_{2}$ treatment showed ROS levels very similar to the uninfected controls [36]. These contradicting results might be due to different type of cells, i.e. HeLa versus ARPE-19, and different MOI of 10:1 and 5:1. Furthermore, DSBs was repaired in $1 \mathrm{~h}$ of ROS removal by NAC, the shortest time point used in the present study, as shown by a dramatical decrease of $\gamma \mathrm{H} 2 \mathrm{AX}$ levels. DSBs repair is very likely to occur and be observed in minutes if shorter time points had been included in our experiment.

Activation of the ATM/CHK2 pathway is involved in many biological processes such as DNA damage repair, cell cycle control and apoptosis etc. For example, the 
active ATM/CHK2 pathway leads to phosphorylation of P53, which is a well-known transcription factor. On one hand, phosphorylation of P53 at Ser25, Ser20 and Ser33 upregulates the expression of DNA binding protein 2, E3 ubiquitin-protein ligase MDM2 and CDC25a. The latter three are the key players in DNA damage repair and cell cycle control, which contribute to survival of wounded cells [42]. On the other hand, phosphorylation of P53 at Ser46 by ATM/CHK2 pathway activates pro-apoptotic genes, leading to apoptosis of wounded cells [43]. We propose that activation of the ATM/CHK2 pathway plays a pivotal role in the host cells to keep a calculated balance between survival and apoptosis during $T$. gondii infection, probably for the benefit of parasite survival.

Identification of parasite molecules causing host cell DNA damage and their molecular interactions with host cells are beyond the scope of the current study. However, it has been reported that $T$. gondii ROP18 kinase interacts with host proteins involving DNA repair and other functions [44]. Ocular and brain lesions caused by T. gondii infections are confirmed in human individuals with significant polymorphism of DNA repair genes [45]. Therefore, T. gondii virulence factors associated with DNA damage and host susceptibility to this damage are worth further investigation.

\section{Conclusions}

Our studies clearly showed that $T$. gondii infection induced DNA double-strand breaks in host cells. This damage was irrelative to apoptosis and occurred only after $T$. gondii invasion. Reactive oxygen species were determined as the major player for DNA double-strand breaks in host cells. The host DNA damage response pathway ATM/CHK2 was activated during $T$. gondii infection, suggesting the DNA damage process may trigger other biological processes as well. More studies are needed to explore the molecular network of DNA double-strand breaks as well as other types of DNA damage in host cells in the future.

\section{Supplementary information}

Supplementary information accompanies this paper at https://doi. org/10.1186/s13071-020-04324-7.

Additional file 1: Figure S1. Serum of T. gondii-infected BALB/C mice blocked T. gondii invasion to HeLa cells. EGFP-RH $\triangle$ ku80 tachyzoites were pre-incubated with either positive mouse serum collected at 6 days post-infection or negative serum harvested at 0 day prior to infection at a 1:10 dilution for $1 \mathrm{~h}$. Afterwards, these parasites were added to HeLa cells at a multiplicity of infection (MOI) of 10:1 at $0 \mathrm{~h}$ when images were taken immediately (left panels). EGFP of the infected HeLa cells was again imaged at $24 \mathrm{hpi}$ by fluorescence microscopy (right panels). Experiments were performed in triplicate. Scale-bars: $100 \mu \mathrm{m}$.
Abbreviations

MOI: Multiplicity of infection; ROS: Reactive oxygen species; NAC: N-acetylcysteine; IFA: Immunofluorescence assay; mAb: Monoclonal antibody; ATM/ CHK2: Ataxia telangiectasia mutated/checkpoint kinase 2; SSBs: Single-strand breaks; DSBs: Double-strand breaks; FBS: Fetal bovine serum; DMEM: Dulbecco's modified Eagle's medium; IMC1: Inner membrane complex 1; SAG1: Surface protein 1; TBS: Tris buffered saline; PBS: Phosphate-buffered saline; H2DCFDA: 2',7'-dichlorodihydrofluorescein diacetate.

\section{Acknowledgements}

We are very grateful to the colleagues Miss Mi Lin and Miss Mingxiu Zhao for their sharing anti-T. gondii IMC1 and SAG1 mouse sera, respectively. We also thank Drs Weiren Dong and Ying Shan (College of Animal Sciences, Zhejiang University) for their technical help on operating plate reader and confocal microscope, respectively.

\section{Authors' contributions}

YY, AFD, YMY, XFZ and SYH conceived and supported the study. HHZ designed and performed the laboratory work. LTP and CQY carried out data analysis. XQC purchased experimental materials and performed a part of laboratory work. $\mathrm{HHZ}$ and $\mathrm{CQY}$ wrote the manuscript. All authors read and approved the final manuscript.

\section{Funding}

This project was supported by the National Natural Science Foundation of China (Grant No. 31672543), Zhejiang Province "Sannongliufang" Science and Technology Cooperation Project (Grant No. 2020SNLF007), the Science and Technology Department of Zhejiang (Grant No. 2012C12009-2) and the National Natural Science Foundation of China (Grant No. 31472184).

\section{Availability of data and materials}

Data supporting the conclusions of this article are included within the article and its additional file. Data and materials can be available upon reasonable request to the corresponding author.

\section{Ethics approval and consent to participate}

Animal experiments were carried out under strict adherence to the guidelines on use of experimental animals of the People's Republic of China. Animal use for this study was approved by the Experimental Animal Ethics Committee of Zhejiang University (permit number: ZJU20160240).

\section{Consent for publication}

Not applicable.

\section{Competing interests}

The authors declare that they have no competing interests.

\section{Author details}

${ }^{1}$ Institute of Preventive Veterinary Medicine, Zhejiang Provincial Key Laboratory of Preventive Veterinary Medicine, College of Animal Sciences, Zhejiang University, Hangzhou 310058, PR China. ${ }^{2}$ Departments of Biomedical Sciences and One Health Center for Zoonoses and Tropical Veterinary Medicine, Ross University School of Veterinary Medicine, P.O. Box 334, Basseterre, West Indies, Saint Kitts and Nevis. ${ }^{3}$ Animals \& Plant Inspection and Quarantine Technology Center of Shenzhen Customs, Shenzhen 518045, PR China. ${ }^{4}$ Institute of Comparative Medicine, College of Veterinary Medicine, Yangzhou University, and Jiangsu Co-innovation Center for Prevention and Control of Important Animal Infectious Diseases and Zoonosis, and Jiangsu Key Laboratory of Zoonosis, Yangzhou 225009, Jiangsu Province, PR China.

Received: 15 June 2020 Accepted: 30 August 2020

Published online: 25 September 2020

\section{References}

1. Molan A, Nosaka K, Hunter M, Wang W. Global status of Toxoplasma gondii infection: systematic review and prevalence snapshots. Trop Biomed. 2019;36:898-925 
2. Mammari N, Halabi MA, Yaacoub S, Chlala H, Darde ML, Courtioux B. Toxoplasma gondii modulates the host cell responses: an overview of apoptosis pathways. Biomed Res Int. 2019;2019:6152489.

3. Wang $Y$, Weiss LM, Orlofsky A. Host cell autophagy is induced by Toxoplasma gondii and contributes to parasite growth. J Biol Chem. 2009;284:1694-701.

4. Ribeiro DA, Pereira PCM, Machado JM, Silva SB, Pessoa AWP, Salvadori DMF. Does toxoplasmosis cause DNA damage? An evaluation in isogenic mice under normal diet or dietary restriction. Mutat Res Genet Toxicol Environ Mutagen. 2004;559:169-76.

5. El-Sayed NM, Aly EM. Toxoplasma gondii infection can induce retinal DNA damage: an experimental study. Int J Ophthalmol. 2014;7:431-6.

6. Hakem R. DNA-damage repair; the good, the bad, and the ugly. EMBO J. 2008;27:589-605.

7. Friedberg EC, McDaniel LD, Schultz RA. The role of endogenous and exogenous DNA damage and mutagenesis. Curr Opin Genet Dev. 2004;14:5-10.

8. Kryston TB, Georgiev AB, Pissis P, Georgakilas AG. Role of oxidative stress and DNA damage in human carcinogenesis. Mutat Res. 2011;711:193-201.

9. Srinivas US, Tan BWQ, Vellayappan BA, Jeyasekharan AD. ROS and the DNA damage response in cancer. Redox Biol. 2019;25:101084.

10. Fang FC. Antimicrobial actions of reactive oxygen species. mBio. 2011;2:e00141.

11. Paiva CN, Bozza MT. Are reactive oxygen species always detrimental to pathogens? Antioxid Redox Signal. 2014;20:1000-37.

12. Matta SK, Patten K, Wang Q, Kim B-H, MacMicking JD, Sibley LD. NADPH oxidase and guanylate binding protein 5 restrict survival of avirulent Type III strains of Toxoplasma gondii in naive macrophages. mBio. 2018;9:e01393.

13. Sun $\mathrm{H}$, Wang $\mathrm{S}$, Zhao $X$, Yao C, Zhuang H, Huang $Y$, et al. Targeted overexpression of cyclic AMP-dependent protein kinase subunit in Toxoplasma gondii promotes replication and virulence in host cells. Vet Parasitol. 2017;243:248-55.

14. Raihan O, Brishti A, Li Q, Zhang Q, Li D, Li X, et al. SFRS11 loss leads to aging-associated cognitive decline by modulating LRP8 and ApoE. Cell Rep. 2019;28:78-90.

15. Sun PR, Gao FF, Choi HG, Zhou W, Yuk J-M, Kwon J, et al. Dipenyleneiodonium induces growth inhibition of Toxoplasma gondii through ROS induction in ARPE-19 cells. Korean J Parasitol. 2019:57:83-92.

16. Halasi M, Wang M, Chavan TS, Gaponenko V, Hay N, Gartel AL. ROS inhibitor $\mathrm{N}$-acetyl-L-cysteine antagonizes the activity of proteasome inhibitors. Biochem J. 2013;454:201-8.

17. Lanz MC, Dibitetto D, Smolka MB. DNA damage kinase signaling: checkpoint and repair at 30 years. EMBO J. 2019;38:e101801.

18. Sharma A, Singh K, Almasan A. Histone H2AX phosphorylation: a marker for DNA damage. Methods Mol Biol. 2012;920:613-26.

19. Rogakou EP, Nieves-Neira W, Boon C, Pommier Y, Bonner WM. Initiation of DNA fragmentation during apoptosis induces phosphorylation of $\mathrm{H} 2 \mathrm{AX}$ histone at serine 139. J Biol Chem. 2000;275:9390-5.

20. Luder CGK, Gross U, Lopes MF. Intracellular protozoan parasites and apoptosis: diverse strategies to modulate parasite-host interactions. Trends Parasitol. 2001;17:480-6.

21. Belmokhtar CA, Hillion J, Segal-Bendirdjian E. Staurosporine induces apoptosis through both caspase-dependent and caspase-independent mechanisms. Oncogene. 2001;20:3354-62.

22. Walters J, Pop C, Scott FL, Drag M, Swartz P, Mattos C, et al. A constitutively active and uninhibitable caspase-3 zymogen efficiently induces apoptosis. Biochem J. 2009;424:335-45.

23. Rastogi S, Cygan AM, Boothroyd JC. Translocation of effector proteins into host cells by Toxoplasma gondii. Curr Opin Microbiol. 2019;52:130-8.

24. Shirahata T, Shimizu K, Suzuki N. Effects of immune lymphocyte products and serum antibody on multiplication of Toxoplasma in murine peritoneal macrophages. Parasitol Res. 1976;49:11-23.

25. Waris $\mathrm{G}$, Ahsan H. Reactive oxygen species: role in the development of cancer and various chronic conditions. J Carcinog. 2006:5:14.

26. Fu L, Xie C. A lucid review of Helicobacter pylori-induced DNA damage in gastric cancer. Helicobacter. 2019;24:e12631.

27. Ribeiro DA, Calvi SA, Picka MM, Persi E, de Carvalho TB, Caetano PK, et al. DNA damage and nitric oxide synthesis in experimentally infected balb/c mice with Trypanosoma cruzi. Exp Parasitol. 2007;116:296-301.
28. Kocyigit A, Keles H, Selek S, Guzel S, Celik H, Erel O. Increased DNA damage and oxidative stress in patients with cutaneous leishmaniasis. Mutat Res Genet Toxicol Environ Mutagen. 2005;585:71-8.

29. Zgur-Bertok D. DNA damage repair and bacterial pathogens. PLoS Pathog. 2013;9:11.

30. Chen Y, Williams V, Filippova M, Filippov V, Duerksen-Hughes P. Viral carcinogenesis: factors inducing DNA damage and virus integration. Cancers. 2014;6:2155-86.

31. Zhou W, Quan JH, Lee YH, Shin DW, Cha GH. Toxoplasma gondii proliferation require down-regulation of host Nox4 expression via activation of PI3 Kinase/Akt signaling pathway. PLoS ONE. 2013;8:e66306.

32. Chen X, Zhong Z, Xu Z, Chen L, Wang Y. 2', $7^{\prime}$ '-Dichlorodihydrofluorescein as a fluorescent probe for reactive oxygen species measurement: forty years of application and controversy. Free Radic Res. 2010;44:587-604.

33. Ciccia A, Elledge SJ. The DNA damage response: making it safe to play with knives. Mol Cell. 2010;40:179-204.

34. Ravanat JL, Cadet J, Douki T. Oxidatively generated DNA lesions as potential biomarkers of in vivo oxidative stress. Curr Mol Med. 2012;12:655-71.

35. Munera Lopez J, Ganuza A, Bogado SS, Munoz D, Ruiz DM, Sullivan WJ $\mathrm{Jr}$, et al. Evaluation of ATM kinase inhibitor KU-55933 as potential antiToxoplasma gondii agent. Front Cell Infect Microbiol. 2019;13:26.

36. Choi SH, Park SJ, Cha GH, Quan JH, Chang NS, Ahn MH, et al. Toxoplasma gondii protects against $\mathrm{H} 2 \mathrm{O} 2$-induced apoptosis in ARPE-19 cells through the transcriptional regulation of apoptotic elements and downregulation of the p38 MAPK pathway. Acta Ophthalmol. 2011;89:E350-6.

37. Han Y, Adeyemi OS, Bin Kabir MH, Kato K. Screening of compound libraries for inhibitors of Toxoplasma growth and invasion. Parasitol Res. 2020;119:1675-81.

38. Caldas LA, Attias M, de Souza W. Dynamin inhibitor impairs Toxoplasma gondii invasion. FEMS Microbiol Lett. 2009;301:103-8.

39. Aruoma Ol, Halliwell B, Hoey BM, Butler J. The antioxidant action of $\mathrm{N}$-acetylcysteine - its reaction with hydrogen-peroxide, hydroxyl radical, superoxide, and hypochlorous acid. Free Radic Biol Med. 1989;6:593-7.

40. Chniguir A, Pintard C, Liu D, Pham My-Chan D, El-Benna J, Bachoual R. Eugenol prevents $\mathrm{fMLF}$-induced superoxide anion production in human neutrophils by inhibiting ERK1/2 signaling pathway and p47phox phosphorylation. Sci Rep. 2019;9:18540.

41. Hwang TL, Yeh SH, Leu YL, Chern CY, Hsu HC. Inhibition of superoxide anion and elastase release in human neutrophils by 3 '-isopropoxychalcone via a cAMP-dependent pathway. Br J Pharmacol. 2006;148:78-87.

42. Roos WP, Thomas AD, Kaina B. DNA damage and the balance between survival and death in cancer biology. Nat Rev Cancer. 2016;16:20-33.

43. Pietsch EC, Sykes SM, McMahon SB, Murphy ME. The p53 family and programmed cell death. Oncogene. 2008;27:6507-21.

44. Cheng L, Chen Y, Chen L, Shen Y, Shen J, An R, et al. Interactions between the ROP18 kinase and host cell proteins that aid in the parasitism of Toxoplasma gondii. Acta Trop. 2012;122:255-60.

45. Smolarz B, Wilczynski J, Nowakowska D. DNA repair mechanisms and Toxoplasma gondii infection. Arch Microbiol. 2014;196:1-8.

\section{Publisher's Note}

Springer Nature remains neutral with regard to jurisdictional claims in published maps and institutional affiliations.

Ready to submit your research? Choose BMC and benefit from:

- fast, convenient online submission

- thorough peer review by experienced researchers in your field

- rapid publication on acceptance

- support for research data, including large and complex data types

- gold Open Access which fosters wider collaboration and increased citations

- maximum visibility for your research: over 100M website views per year

At BMC, research is always in progress.

Learn more biomedcentral.com/submissions 